\title{
Ensino da Química e Segurança
}

Na sequência da realização de um ciclo de acções de formação de Professores do Ensino Secundário, organizado pelo Sector de Formação de Professores da Direcção Regional da Educação de Lisboa e que teve lugar em 11-12 e 14-15/9/89, incidindo sobre a temática da Segurança no Ensino da Química, os 19 participantes concordaram nos pontos a seguir e propuseram que fossem tomadas imediatamente as medidas indicadas, que têm o apoio da Sociedade Portuguesa de Química*.
* Cópias enviadas ao Sr. Ministro da Educação; Sr. Secretário de Estado da Reforma Educativa; $\mathrm{Sr}^{3}$ Directora Regional da Educação de Lisboa; Sr. Director-Geral dos Equipamentos Educativos; e Sociedade Portuguesa de Química para publicação no seu Boletim.

Na sede da Sociedade Portuguesa de Química encontra-se à disposição dos interessados a documentação distribuída aos participantes do Curso, que aí pode ser consultada. A documentação inclui tópicos sobre os seguintes temas: Princípios Gerais sobre Segurança em Laboratórios Químicos

Equipamento Protector e Situações de Emergência

Segurança e Técnicas Laboratoriais

Fontes de Informação sobre Química e Segurança

Armazenagem Segura de Produtos Químicos

Recuperação e Eliminação de Resíduos de Produtos Químicos

Segue-se ainda uma parte experimental, com algumas experiências laboratoriais seleccionadas para ilustrar as técnicas utilizadas num laboratório de química moderno.

Este Curso foi realizado com a colaboração de Eng ${ }^{\mathrm{a}}$ Lucélia Pombeiro (LNETI), Dr ${ }^{a}$ Maria do Céu Costa (LNETI), Dr ${ }^{3}$ Teresa Maria Pinto Basto (Faculdade de Ciências de Lisboa), Dr ả Lucinda Vaz dos Reis (LNETI), e da auxiliar Gracinda Rodrigues (LNETI).

\section{Formação e Informação}

- Os Directores de Instalações dos vários grupos ou disciplinas, de todas as escolas, devem obrigatoriamente frequentar acções de formação estruturadas de acordo com os problemas específicos de segurança da sua área.

- Em particular os professores de química deverão frequentar pelo menos uma acção de formação específica sobre segurança e actualização em química no mínimo de 3 em 3 anos, incluindo uma parte experimental para contactarem com novos métodos, novos equipamentos e novos materiais. - Deve ser distribuída por todas as escolas, uma folha/folheto informativo (1 por cada período escolar) sobre aspectos relativos a segurança em química, que a Secção de Segurança da Sociedade Portuguesa de Química se propõe elaborar gratuitamente, desde que o Ministério da Educação assegure a sua reprodução e distribuição.

- Deve ser equipada, actualizada e estar em funcionamento a biblioteca de todas as escolas.

- Deve ser divulgado o Centro de Informação Bibliográfica do Ministério da Educação, e activada a sua interacção com as bibliotecas escolares a nível nacional, de molde a que os professores possam obter documentação relevante para a sua actualização no exercício da actividade docente.

\section{Instalações e Medidas de Segurança}

- Em todas as escolas deve ser organizado um plano de evacuação das instalações em caso de acidente grave, com a colaboração da corporação de bombeiros local, que será testado duas vezes por ano através de exercícios de simulação.

- Deve proceder-se à imediata eliminação do gás de todos os laboratórios de química, com substituição dos bicos de Bunsen por sistemas de aquecimento eléctricos de maior segurança.

- Todos os laboratórios devem obrigatória e efectivamente ter um técnico auxiliar de laboratório.

- A execução de experiências laboratoriais em cada escola deve sempre pressupôr a existência de instalações laboratoriais adequadas a essas mesmas experiências.

- O novo curriculum em preparação/discussão para a área da

\footnotetext{
"Departamento de Tecnologia de Indústria Química (LNETI), Estrada das Palmeiras, 2745 Queluz.
} 
química deverá ter em consideração a insuficiência de meios dos laboratórios escolares.

- A disciplina de Quimicotecnia só deve ser ministrada em escolas que disponham de um laboratório de química devidamente apetrechado (como exemplo de uma situação de risco grave veja-se o caso da Escola Secundária do Seixal $n^{\circ} 1$ ).

- Todos os laboratórios de química devem ser equipados com no mínimo uma hote (nicho) com ventilação eficiente que será efectuada por um motor de extracção (a ventilação natural é inadequada e a deslocação de ar por diferença de temperatura, envolvendo chamas nuas, extremamente perigosa).

- Os professores de química só devem fazer experiências envolvendo produtos químicos perigosos ou reacções químicas em que haja formação de gases ou produtos potencialmente perigosos no laboratório e nunca nas salas de aula.

- O laboratório deve ser exclusivamente reservado para a execução de trabalhos experimentais, não devendo ser utilizado para leccionar outras disciplinas.

- Todas as escolas que têm laboratório de química devem dispôr de um armazém para produtos químicos.

- Deve ser desde já fornecido aos laboratórios escolares material para pipetagem de líquidos, de modo a que os alunos não se vejam compelidos a efectuar pipetagens com a boca, com possibilidade de contacto/ingestão de líquidos tóxicos e/ ou corrosivos.

- O equipamento protector a fornecer aos laboratórios escolares deve incluir obrigatoriamente óculos de segurança e luvas resistentes aos produtos químicos.

\section{Produtos Químicos Perigosos nas Escolas}

- Devem desde já ser banidas do curriculum escolar todas as experiências que envolvam reagentes cujo perigo potencial ou inadequação de instalações laboratoriais não justifique o risco da sua utilização. Entre estes reagentes contam-se os cianetos (altamente tóxicos), o benzeno e o amianto (cancerígenos) e o ácido pícrico (muito tóxico e explosivo quando seco, tendo sido outrora usado no tratamento de queimaduras).

- Deve ser solicitado de imediato a todas as escolas que efectuem um levantamento das existências de produtos químicos deteriorados, não rotulados, desnecessários, anti- gos, que suscitem dúvidas quanto à sua segurança e/ou desnecessários em armazém, incluindo ainda os que devem ser banidos das escolas, numa acção alargada a todas as Direcções Regionais de Educação. Após a recolha das listas (com indicação de nome de cada produto, quantidade existente e data de aquisição), será estudado o modo a proceder à recolha e destruição desses produtos químicos, num local a designar já que a grande maioria das escolas não possui laboratórios devidamente equipados nem com condições de segurança mínimas. - Deve ser feita a reavaliação das experiências laboratoriais recomendadas nos manuais escolares de química, por se verificar que algumas delas envolvem reagentes ou formação de produtos cujo risco não justifica a sua execução na escola, ou pelo menos naquelas cujo laboratório não reúne condições de segurança. Essa reavaliação poderá ser feita em colaboração com a Sociedade Portuguesa de Química.

- Futuros manuais escolares de química deverão obrigatoriamente incluir informação sobre segurança para cada experiência laboratorial recomendada.

\section{Actualização de Matérias, Técnicas e Tipologias}

- A química experimental ensinada nas escolas deve acompanhar o progresso desta ciência, ilustrando o trabalho do químico actual e não, como sucede presentemente, o trabalho do químico de há cinco décadas.

- O desacompanhamento dos progressos da química experimental que se verifica nas escolas traduz-se na total inadequação da tipologia para esta área, que deve ser urgentemente revista em termos programáticos, de equipamentos e materiais.

- Em particular, a nível da formação específica e técnica, a química do tubo de ensaio, do tubo de vidro dobrado à chama de um bico de gás e da rolha furada, por desactualizada, não contribui nem para a preparação dos alunos para inserção na vida activa nem para o prosseguimento dos seus estudos a nível universitário.

- A nova tipologia deverá estar em sintonia com o novo curriculum aprovado para a área da química e incluir equipamentos actuais e material de vidro normalizado em «kits», o que permitirá a sua utilização em operações diversificadas, traduzindo-se em apreciável economia de meios.
MANGANÊS, de magnes, ou magnete, por o seu minério ter sido inicialmente confundido com a magnetite; descoberto em 1774. Confere ao aço dureza e flexibilidade, assim como aos ossos dos animais; sem ele, os ossos seriam esponjosos e quebrar-se-iam com facilidade; é activador de muitas enzimas.

FERRO, de ferrum, antigo nome latino; foi o primeiro metal a ser utilizado pelo homem pré-histórico. É o quarto elemento mais abundante e o metal mais barato. É o ingrediente básico do aço. Faz parte da composição da hemoglobina, tendo como função transportar o oxigénio no fluxo sanguíneo.

COBALTO, de kobald, ou mau espírito, devido ao seu minério ser venenoso; descoberto em 1735. Durante séculos, os sais azuis de cobalto têm vindo a colorir porcelanas e esmaltes. As suas ligas são usadas em propulsores a jacto e o seu isótopo radioactivo no tratamento do cancro. 